Professor Liliana DONATH, PhD

E-mail: liliana.donath@e-uvt.ro

Department of Finance

West University of Timișoara

Professor Gabriela MIRCEA, PhD

E-mail: gabriela.mircea@e-uvt.ro

Department of Business Information System

West University of Timişoara

Professor Mihaela NEAMTU, PhD

E-mail: mihaela.neamtu@e-uvt.ro

Department of Economics and Modelling

East European Research Centre for Economics and Business

West University of Timişoara

Ionela OPREA, PhD

E-mail: ionela.oprea@e-uvt.ro

Department of Finance

West University of Timişoara

\title{
PREVENTING CONTAGION IN FINANCIAL MARKETS. AN ANALYSIS OF THE CONTROLLED FINANCIAL RISK WITH TIME DELAY
}

Abstract.The article analyses the evolution of the financial risk contagion considering a mathematical model with time delay using the occurrence value, the analyzed value and the controlled value of the risk. The aim of the paper is to find the equilibrium point and the necessary conditions for its asymptotic stability. The existence of the oscillatory solutions is studied, taking the time delay as a bifurcation parameter. To verify the theoretical findings, numerical simulations are carried out. Conclusions show that financial risks can be controlled and the appropriate moment when measures should be taken to prevent contagion can be determined. Financial explanations and discussions are provided throughout the paper as support for the mathematical model and its practical use.

Keywords: Dynamical systems, Equilibrium, Controlled risk, Modelling, Numerical simulations.

JEL Classification: C02,C61, C62, C63, E44

DOI: $10.24818 / 18423264 / 54.2 .20 .07$ 


\section{Introduction}

Over the last decades, the increased frequency of economic and financial crises has shifted attention towards risks and the possibility of their spreading from one market to another through contagion. The globalization of financial markets raised the awareness of institutions and investors alike that contagion is not manifested solely as cross-border contagion, but touches all transactions and economies, irrespective whether they are developed or emerging economies.

Since risk contagion is a complex concept embedding a large number of indicators (from the political and security ones to those referring to macroeconomics, banking systems and financial markets) there is no straightforward definition that would accommodate all points of view. Therefore, when studying risk contagion, it should be analysed in perspective, in a defined context, using the appropriate methodology and timeframe.

Usually, during financial stability, complacency is characterizing investors' behaviour hence not disturb the tranquillity of the markets. But when the activity starts to heat up, information about the evolution of assets' prices is becoming important and the mood of investors, often, starts to reflect anxiety as they shift their investing interest from one market to another inflaming the already germinating financial crises. During such turbulent times, bond prices (considered the safest securities) are carefully watched as indicators of the macroeconomic evolutions as well as gold prices (as a store of value), metals' and oil prices as indices of industrial production. Anxiety can be, also, aggravated by the noise and rumours in the media that may trigger agglomeration by attachment (or herd behaviour) that negatively impacts on financial asset prices. The shock waves propagate generally from developed countries across markets worldwide and are absorbed by the most vulnerable ones in emerging economies.

In the process of contagion, behaviours matter, because they underlie a fundamental determinant of financial stability, i.e. trust and confidence in future positive evolution. Once it is undermined, companies and households refrain from spending and investing, bringing the economy to a halt. Under these circumstances, risk management is of utmost importance in preventing contagion.

The mission of the study is to find a mathematical model, based on which macro- prudential measures can be designed and implemented to prevent the perpetuation of oscillatory movements and contagion on the financial market.

In the present paper, a mathematical model with time delay is used to find the conditionality on the system's parameters so that the equilibrium point is asymptotically stable and the stability of the market is restored.

The motivation for this approach relies on the fact that the mathematical formalisation of any scientific concepts related to most research fields (biological, chemical, economical, financial, etc.) ultimately defines dynamical systems (Kuznetsov, 1998). Moreover, the state of these systems (either past or future) is predictable unless the laws that govern their development remain unchanged. 
Preventing Contagion in Financial Markets. An Analysis of the Controlled Financial Risk with Time Delay

A high degree of abstraction, based on logic, is fundamental for mathematical models. But, once the simulation verifies the theoretical assumptions, the model may be adapted to any market situations and empirically tested.

To our best knowledge, the existing literature applies the time delay to the occurrence risk or the current market controlled risk. This paper contributes to the literature and to the understanding of financial risks by considering the time delay to the analysed risk. Consequently, it helps to identify the most appropriate moment when macro-prudential measures can be implemented.

The article proceeds as follows. The literature review is provided in Section 2. Mathematical model and stability analysis of the financial risks with and without time delay are discussed in Section 3. Numerical simulations are run to check the theoretical findings. The remainder of the paper is dedicated to Conclusions.

\section{Literature review}

The monetary and financial authorities regard the assurance of financial stability on all the three segments of the financial market (i.e. the banking, insurance and capital markets) as their main objective. For this purpose, they activate a set of measures that are meant to correct the market mechanisms whenever they anticipate the deepening of vulnerabilities and crises (Frait\&Komárková, 2011).

In order to be effective, the perceived measures should consider the stance of the financial cycle as shown in Figure 1.

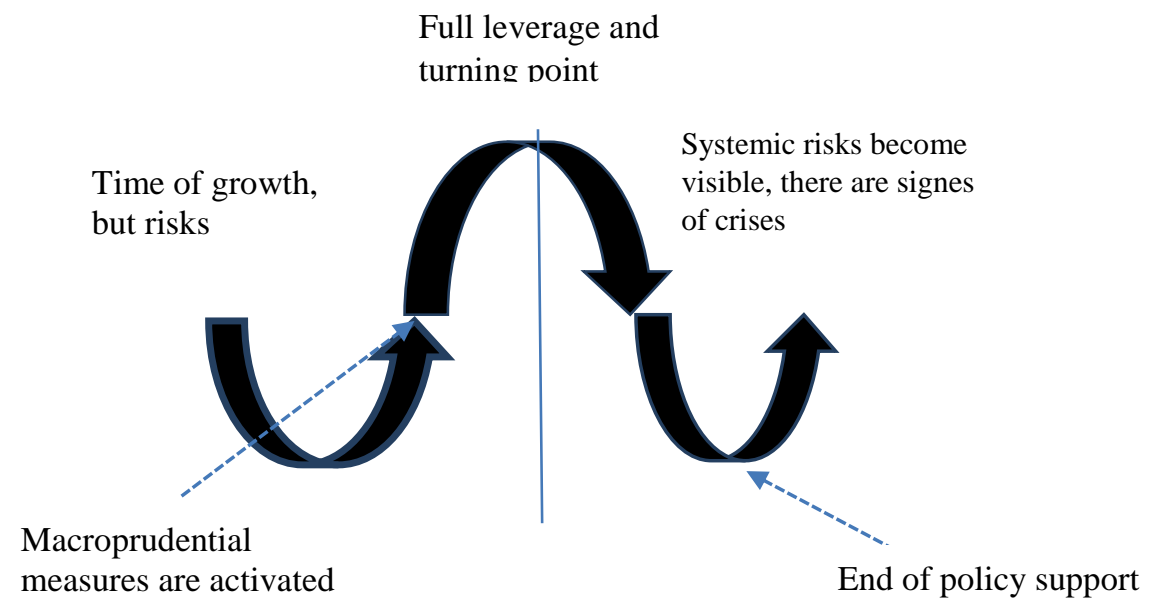

Figure 1. The accumulation of systemic risk

Source: Authors' own representation based on Frait and Komárková 2011

DOI: 10.24818/18423264/54.2.20.07 
Macro-prudential policies are meant to prevent systemic risks or, when manifested, to limit their effects. From the prevention perspective, the financial stability analysis considers the timely identification of the systemic risks' congestion as a prerequisite of financial instability and eventually the outburst of crises.

Figure 1 shows the accumulation of systemic risk (left side) translated into crisis (right side). The depth and intensity of the outcome depend on the ability to identify the amplitude and the frequency of the oscillations and, following a detailed analysis, to pinpoint the sequence of the cycle where the measures should be taken so that the equilibrium point is asymptotically stable.

Scholars have extensively discussed risk contagion over the last decades, and the challenges financial authorities face in mitigating their consequences (Gao\&Xu, 2019). Extensive literature has been dedicated to understanding contagion which cannot always be related to financial crises, some authors arguing that it may be interpreted as market interdependencies (Caporin, Pelizzon, Ravazzolo\&Rigobon, 2013). Since its meaning is debatable, the following statement can be considered as acceptable, i.e. a significant increase in crossmarket linkages after a shock to an individual country or group of countries (Dornbusch, Park \&Claessens, 2000), or, as visible changes in the way countryspecific shocks are transmitted internationally (Wälti, 2003). Other researches show that correlations occur in stock markets during turmoil and contagion is noticeable (Asgarian\&Nossman, 2011).

Gong, Smith \&Zou (2007), discuss the relationship between the hyperbolic discounting effect on risk and stock prices, arguing that is might also have significant macroeconomic effects.

The strength by which the financial instability propagates, contaminating other financial systems, depends on the resilience and/or the residual stance of the recipient system. The solidity of the economy, of the financial institutions and of the market mechanisms is crucial in resisting or absorbing the induced vulnerabilities.

From this perspective, there are significant institutional differences in developed economies, compared to the emerging ones, implying that the transmission channels of instability differ. On a long trend, the rate of inflation in developed countries is rather less volatile, the currencies are quite stable and, consequently, long term national currency denominated credit contracts are preferred by businesses and households, whereas in most emerging economies, because of the macroeconomic conditions, of higher inflation rates and volatile exchange rates, short term credit contracts denominated in a foreign currency are preferred. Thus, exposure to foreign exchange risks is higher as well as the level of nonperforming loans. Baur refers to flight-to-quality and flight-from-quality when either the stock market or the bond markets are subject to uncertainty or crisis (Baur\&Lucey, 2009). To the extent to which these markets are globally 
Preventing Contagion in Financial Markets. An Analysis of the Controlled Financial Risk with Time Delay

interconnected, contagion is ready to spread on weaker economies, such as the emerging ones.

It is acknowledged that emerging markets have largely benefited from the globalisation and the development of technology to improve market mechanisms, but are still more vulnerable to contagion and outburst of crises. Since they are lagging behind the developed markets, they are more exposed to risk spill-over and residual contagion that add to the domestic and regional real economy weaknesses. In addition, swiftly changing information triggers investors' attention to the movement of stock markets that replicate similar situations already encountered on markets driven by similar factors (Fang, Yang \& Lei, 2019).

It can be demonstrated that residual contagion has a more severe impact since its causes lie outside the factors that are controllable by the national or regional financial authorities. In addition, it is documented (Gulzar, Kayani, Xiaofeng, Ayub\&Rafique, 2018) that countries that are less co-integrated are most exposed to spill-over, risk managers and investors significantly contributing to their vulnerabilities since they redirect their funds towards more stable markets. Thus, it is safe to state that emerging markets are left to struggle in a vicious circle that cannot be reversed until a positive externality (spill-over) occurs that would ignite transactions and increase returns.

Compared to the developed economies, where the banking systems are major financial intermediaries and thus most often are at the core of financial crises, in emerging economies, financial intermediation is less developed and, since they have a residual position as importers of goods and services the crises are manifested through the foreign exchange market.

Since the financial markets in these economies are less developed and less interconnected globally, the accumulated risks are internalized (and not spilt over) being aggravated by the "imported" crises through the foreign exchange markets. Moreover, in case exchange rate mechanisms are not consistent with the macroeconomic stance they play a major role in risk contagion (Davis, 2003). Therefore, it explains the sharper decline of the GDP and the longer time needed to rebalance the economy. In the context of globalisation, the intensification of international financial flows contributes to the transmission of vulnerabilities among financial markets.

The interconnections between individual financial institutions can be considered as channels through which the contagion propagates and thus considered as the core determinant of financial risks.

DOI: 10.24818/18423264/54.2.20.07 
Liliana Donath, Gabriela Mircea, Mihaela Neamtu, Ionela Oprea

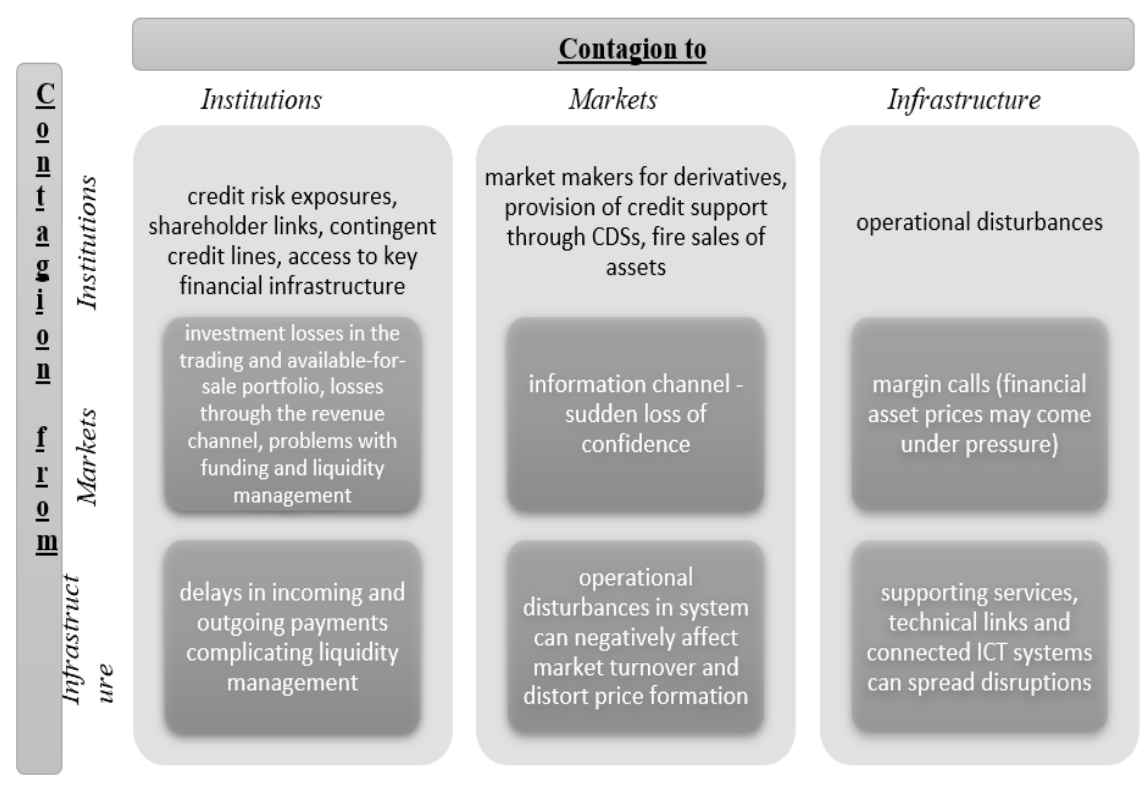

Figure 2. Risk contagion matrix

Unless complete information is available to financial institutions, they are not able to judge the impact of their own financial behaviour on other institutions they connect with. For the same reason, they are unable to safeguard themselves from the negative impact of other institutions' behaviour. Consequently, if an institution is part of a financial network than it bears the network risk since it cannot efficiently or speculatively hedge against the other institutions in the network (Haldane, 2009). Nevertheless, it can be argued that negative shocks are either spread or absorbed according to the phase of the financial cycle. The 2008 crisis is a good example of a nonspecific financial downturn that it exceeds an ordinary analysis. Therefore, a possibility to analyse financial contagion is to consider the decisions of all actors that have led to such an abrupt market failure.

Under such complex circumstance, the literature approaches the financial risks' analysis from various stand points that involve different research methods.

For instance, Trabelsi, using a bivariate DCC-GARCH model conclude that the subprime crises generated contagion while the debt crises can be considered as interdependencies for most countries included in their analysis (Trabelsi\&Hmida, 2017).

Another strand of literature rather analyses the Credit Risk Contagion in the CRT Market using an entropy spatial model as a core of risk transfer on the financial markets (Chen, Chen, Li \& Wang, 2015), while Alghalith, Guo, Wong \& Zhu (2016) find two dynamic models for the impact of background risk on the optimum portfolio. 
Preventing Contagion in Financial Markets. An Analysis of the Controlled Financial Risk with Time Delay

Or, more recently Zhang and Zhu (2019) discuss the Hopf bifurcation at the equilibrium point to analyze the stability of financial systems as a dynamical behaviour.

Literature also emphasizes the existence of shift contagion, using a synchronicity measure demonstrating that synchronicity between financial markets does not occur only during the crises (Mink \&Mierau 2009).

Nonetheless, it can be argued that markets are rational, but the investors that act on the financial markets are often either overoptimistic or over pessimistic, thus disturbing the market mechanisms. Kahneman and Tversky in their seminal work, show that investors make their decisions randomly, most of the time, thus deviating from the rational utility (Kahneman\&Tversky, 1979). Moreover, Fischhoff shows that investors are rather anchored in their past decision pattern and expecting that the future outcomes resemble the past ones (Fischhoff, Slovic\& Lichtenstein, 1977).

Consequently, a major implication is that the market cannot, on its own, produce results meant to optimize the social welfare because of its imperfections, on one hand, and the psychological characteristics of the investors on the other hand. It seems that an external constraint is necessary (e.g. a regulated intervention) to avoid catastrophic failure and allow markets to bounce back to the optimum equilibrium (Grosse, 2010). Such interventions did occur during the 2008 crises but since they were not tailored to address the causes of market failure the residual persistence of its consequences is still visible.

Starting from the major psychological characteristics of the American markets as drivers of the global economy, i. e. over-optimism and the inability of the investors to address and overcome the temporary downturn of assets' prices, the main behavioural aspects of the crises can be identified.

Therefore, one can assume that finding the most appropriate moment when measures should be taken to prevent crisis and/or mitigate risk contagion is important for agents and financial authorities alike.

\section{Mathematical model and stability analysis}

For the purpose of the study, a deterministic mathematical model was chosen to analyze three stances of the financial risk: the analyzed value, the occurrence and controlled value. The reason behind the decision is that targeting risks that cause contagion, may trigger the best, timely measures to prevent crises given that in dynamic systems, bifurcations are visible when a slight change of the bifurcation parameter's value leads to a qualitative or topological change of behaviour (Karaaslani, 2012).

DOI: $10.24818 / 18423264 / 54.2 .20 .07$ 


\subsection{An analysis of the deterministic mathematical model without delay}

In Zhang (Zhang, Liu, Zheng\& Liu, 2013), the risk management process in the financial market is given by:

$$
\left\{\begin{array}{c}
\dot{R}(t)=m U(t)-R(t)-n(R(t)-d U(t)) V(t) \\
\dot{U}(t)=r R(t)-U(t)-R(t) V(t) \\
\dot{V}(t)=R(t) U(t)-V(t)+k V(t)
\end{array}\right.
$$

where $\mathrm{R}, \mathrm{U}$ and $\mathrm{V}$ stand for the occurrence value of the risk, the analyzed value of the risk and the controlled value of the risk in the current market, respectively. The value of the risk controlled by analysis is $\mathrm{U}(\mathrm{t}) \mathrm{V}(\mathrm{t})$, the value of the risk controlled by its occurrence is $\mathrm{R}(\mathrm{t}) \mathrm{V}(\mathrm{t})$ and $\mathrm{U}(\mathrm{t}) \mathrm{R}(\mathrm{t})$ stands for the value of the analyzed risk by occurrence. Parameters $\mathrm{m}, \mathrm{n}, \mathrm{d}$ and $\mathrm{r}$ are positive real numbers representing the analysis of the risk efficiency, the risk satisfaction rate, the controlled risk efficiency and the transmission rate of the previous risk, respectively. The real parameter $\mathrm{k}$ is the distortion coefficient of risk control.

For $m=n+1, n d=1$, the conditions for the stability and bifurcation of system (1) are found.

Firstly, the following system is considered:

$$
\left\{\begin{array}{c}
\dot{R}(t)=-p_{1} R(t)+p_{2} U(t)+p_{3} U(t) V(t) \\
\dot{U}(t)=r R(t)-U(t)-R(t) V(t) \\
\dot{V}(t)=R(t) U(t)-(q-k) V(t)
\end{array}\right.
$$

where $\mathrm{p}_{1}, \mathrm{p}_{2}, \mathrm{p}_{3}, \mathrm{r}, \mathrm{q}$ and $\mathrm{k}$ are positive constants.

If $\mathrm{p}_{1}=\mathrm{p}_{2}=\delta, \mathrm{p}_{3}=1, \mathrm{q}-\mathrm{k}=\mathrm{b}$, system (1) is studied.

The equilibrium states for the system (1) are obtained by solving the algebraic system:

$$
\begin{aligned}
& -\mathrm{p}_{1} \mathrm{R}+\mathrm{p}_{2} \mathrm{U}+\mathrm{p}_{3} \mathrm{UV}=0 \\
& \mathrm{rR}-\mathrm{U}-\mathrm{RV}=0 \\
& \mathrm{RU}-(\mathrm{q}-\mathrm{k}) \mathrm{V}=0
\end{aligned}
$$

Positive solutions of (2) are searched because in the financial market the three state variables are nonnegative.

System (1) has the trivial equilibrium state $\mathrm{E}_{0}=(0,0,0)$ and the non-trivial one is given by:

Proposition 1. If $\Delta=\left(p_{2}-p_{3} r\right)^{2}-4 p_{3}\left(p_{1}-p_{2} r\right)>0$ and $p_{1}-p_{2} r<$ $0, q>k$ are satisfied, then the nontrivial equilibrium state of the system (1) is $\mathrm{E}_{1}=\left(\mathrm{R}_{1}, \mathrm{U}_{1}, \mathrm{~V}_{1}\right)$, where: 
Preventing Contagion in Financial Markets. An Analysis of the Controlled Financial Risk with Time Delay

$$
R_{1}=\sqrt{\frac{(q-k) V_{1}}{r-V_{1}}}, U_{1}=R_{1}\left(r-V_{1}\right)
$$

and $V_{1}$ is the positive root of the equation:

$$
p_{3} x^{2}+\left(p_{2}-p_{3} r\right) x+p_{1}-p_{2} r=0 .
$$

In what follows we study the local stability for the system (1).

By linearizing system (1), the Jacobian matrix at $\mathrm{E}_{0}$ is:

$$
J=\left(\begin{array}{ccc}
-\mathrm{p}_{1} & \mathrm{p}_{2} & 0 \\
\mathrm{r} & -1 & 0 \\
0 & 0 & -\mathrm{q}+\mathrm{k}
\end{array}\right)
$$

The characteristic equation corresponding to (3) is given by:

$$
(\lambda+\mathrm{q}-\mathrm{k})\left(\lambda^{2}+\left(\mathrm{p}_{1}+1\right) \lambda+\mathrm{p}_{1}-\mathrm{rp}_{2}\right)=0
$$

and the corresponding eigenvalues are:

$$
\lambda_{1}=k-q, \lambda_{2,3}=-\frac{p_{1}+1}{2} \pm \frac{1}{2} \sqrt{\left(p_{1}+1\right)^{2}+4\left(p_{2} r-p_{1}\right)}
$$

and therefore $\mathrm{E}_{0}$ is an unstable equilibrium point.

The Jacobian matrix at $\mathrm{E}_{1}$ is:

$$
J=\left(\begin{array}{lll}
a_{11} & a_{12} & a_{13} \\
a_{21} & a_{22} & a_{23} \\
a_{31} & a_{32} & a_{33}
\end{array}\right)
$$

where

$$
\begin{array}{ll}
a_{11}=-p_{1}, & a_{12}=\frac{p_{1} R_{1}}{U_{1}}, \quad a_{13}=p_{3} U_{1}, \\
a_{21}=\frac{U_{1}}{R_{1}}, & a_{22}=-1, \quad a_{23}=-R_{1}, \\
a_{31}=U_{1}, \quad a_{32}=R_{1}, \quad a_{33}=-1+k .
\end{array}
$$

DOI: 10.24818/18423264/54.2.20.07 
For the nontrivial equilibrium $\mathrm{E}_{1}=\left(\mathrm{R}_{1}, \mathrm{U}_{1}, \mathrm{~V}_{1}\right)$ the characteristic equation corresponding to (4) becomes:

where

$$
\lambda^{3}+\mathrm{m}_{2} \lambda^{2}+\mathrm{m}_{1} \lambda+\mathrm{m}_{0}=0
$$

$$
\begin{aligned}
m_{2}= & -\left(a_{11}+a_{22}+a_{33}\right), m_{1}=-q\left(a_{11}+a_{22}\right)-a_{13} a_{31}-a_{23} a_{32}, \\
& m_{0}=-a_{13}\left(a_{21} a_{32}-a_{22} a_{31}\right)-a_{23}\left(a_{12} a_{31}-a_{11} a_{32}\right) .
\end{aligned}
$$

Using the Routh-Hurwitz criterion, the equilibrium $\mathrm{E}_{1}$ is locally asymptotically stable is if the following conditions are satisfied:

$$
m_{2}>0, m_{0}>0, m_{2} m_{1}-m_{0}>0
$$

If the stability of the system is reached then the market risk will be in a controllable range and, consequently, the market, through its own mechanisms, is able to adjust the risk so that it remains neutral and the economic activities are not affected. Else, the risk becomes uncontrollable and measures are needed to control it.

\subsection{An analysis of the deterministic mathematical model with time delay}

As in (Lutoshkin\&Yamaltdinova, 2018)and we consider that the economic process in not instantaneous. In this subsection, it is supposed that the previously analyzed risk affects the rate of change for the occurrence value of the risk and the value of the risk that is analyzed. In this context the time delay $\tau>0$ is introduced as follows:

$\left\{\begin{array}{c}\dot{R}(t)=-p_{1} R(t)+p_{2} U(t-\tau)+p_{3} U(t) V(t) \\ \dot{U}(t)=r R(t)-U(t-\tau)-R(t) V(t) \\ \dot{V}(t)=R(t) U(t)-V(t)+k V(t)\end{array}\right.$

By linearizing system (6), the Jacobian matrix at an equilibrium state $\mathrm{E}=\left(\mathrm{R}_{0}, \mathrm{U}_{0}, \mathrm{~V}_{0}\right)$ is given by:

$$
J=\left(\begin{array}{lll}
a_{11} & b_{12} & a_{13} \\
a_{21} & b_{22} & a_{23} \\
a_{31} & a_{32} & a_{33}
\end{array}\right)
$$

where 
Preventing Contagion in Financial Markets. An Analysis of the Controlled Financial Risk with Time Delay

$$
\begin{aligned}
& \mathrm{a}_{11}=-\mathrm{p}_{1}, \quad \mathrm{a}_{12}=\mathrm{p}_{2}+\mathrm{p}_{3} \mathrm{~V}_{0}, \quad \mathrm{~b}_{13}=\mathrm{p}_{3} \mathrm{U}_{0}, \\
& \mathrm{a}_{21}=\mathrm{r}-\mathrm{V}_{0}, \quad \mathrm{a}_{22}=-1, \quad \mathrm{~b}_{23}=-\mathrm{R}_{0}, \\
& \mathrm{a}_{31}=\mathrm{U}_{0}, \quad \mathrm{a}_{32}=\mathrm{R}_{0}, \quad \mathrm{a}_{33}=-1, \mathrm{~b}_{33}=\mathrm{k} .
\end{aligned}
$$

The characteristic equation is given by:

$$
\lambda^{3}+a_{2} \lambda^{2}+a_{1} \lambda+a_{0}-\left(b_{2} \lambda^{2}+b_{1} \lambda+b_{0}\right) e^{-\lambda \tau}=0
$$

where

$$
\begin{gathered}
a_{2}=q+p_{1}+1, a_{1}=q\left(1+p_{1}\right)-p_{3} U_{0}^{2}, \\
a_{0}=-p_{3} U_{0}\left(\left(r-V_{0}\right) R_{0}+U_{0}\right), b_{2}=k, b_{1}=k\left(1+p_{1}\right)+R_{0}^{2}, b_{0} \\
=R_{0}\left(U_{0}\left(p_{2}+p_{3} V_{0}\right)+p_{1} R_{0}\right)
\end{gathered}
$$

The introduction of the time delay can lead to oscillatory solutions and the equilibrium point can change from stable to unstable. In order to study their existence we consider $\lambda=\mathrm{i} \omega,(\omega>0)$ a root of (8). A positive root for the following equation is searched for:

$\mathrm{x}^{6}+\left(\mathrm{m}_{2}^{2}-2 \mathrm{~m}_{1}-\mathrm{n}_{2}^{2}\right) \mathrm{x}^{4}+\left(\mathrm{m}_{1}^{2}-2 \mathrm{~m}_{0} \mathrm{~m}_{2}+2 \mathrm{n}_{0} \mathrm{n}_{2}-\mathrm{n}_{2}^{2}\right) \mathrm{x}^{2}+\mathrm{m}_{0}^{2}-\mathrm{n}_{0}^{2}=0$.

The parameters of the model are supposed to satisfy $m_{0}+n_{0}>$ 0 . Because $m_{0}-n_{0}<0$ equation (9) has a positive root $\omega_{0}$. Therefore, the critical value of the bifurcation parameter is:

$$
\tau_{0}=\frac{1}{\omega_{0}}\left[\arccos \frac{\mathrm{A}\left(\omega_{0}\right)}{\mathrm{B}\left(\omega_{0}\right)}+2 \mathrm{n} \pi\right], \mathrm{n}=0,1,2, \ldots
$$

where

$$
\mathrm{A}\left(\omega_{0}\right)=-\mathrm{a}_{2} \omega_{0}^{2}\left(\mathrm{~b}_{2} \omega_{0}^{2}-\mathrm{b}_{0}\right)+\omega_{0} \mathrm{~b}_{1}\left(\mathrm{a}_{1} \omega_{0}-\omega_{0}^{3}\right), \mathrm{B}\left(\omega_{0}\right)=\left(\mathrm{b}_{2} \omega_{0}^{2}-\mathrm{b}_{0}\right)^{2}+\omega_{0}^{2} \mathrm{~b}_{1}^{2}
$$

If $\lambda=\lambda(\tau)$ is a root of (8) by a direct calculation we obtain:

$$
\operatorname{Re}\left(\left.\frac{\mathrm{d} \lambda(\tau)}{\mathrm{d} \tau}\right|_{\tau=\tau_{0,}, \lambda=i \omega_{0}}\right) \neq 0
$$

DOI: 10.24818/18423264/54.2.20.07 
that ensures the existence of a Hopf bifurcation.

The previous analysis can be summarized as:

Proposition 2. Under the conditions (4) the equilibrium point $\mathrm{E}$ is locally asymptotically stable if $\tau<\tau_{0}$. In addition, if (11) holds, then for $\tau=\tau_{0}$ the system (6) exhibits a Hopf bifurcation at the equilibrium point.

\section{Numerical simulation}

In this section the Matlab software is used in order to verify the theoretical findings: $\mathrm{p}_{1}=25 \mathrm{p}_{2}=25 \mathrm{p}_{3}=1, \mathrm{r}=5.8, \mathrm{q}-\mathrm{k}=2.8$. The equilibrium point of (6) is $\mathrm{R}_{0}=7, \mathrm{U}_{0}=7.93, \mathrm{~V}_{0}=10.97$. If there is no delay, conditions (5) are satisfied and the equilibrium point $(7,7.93,10.97)$ is locally asymptotically stable. In Figure 3 , the orbits of the occurrence value of the risk, $(t, R(t))$, the analysed value of the risk $(t, U(t))$ and the controlled value of the risk $(t, V(t))$ are displayed.
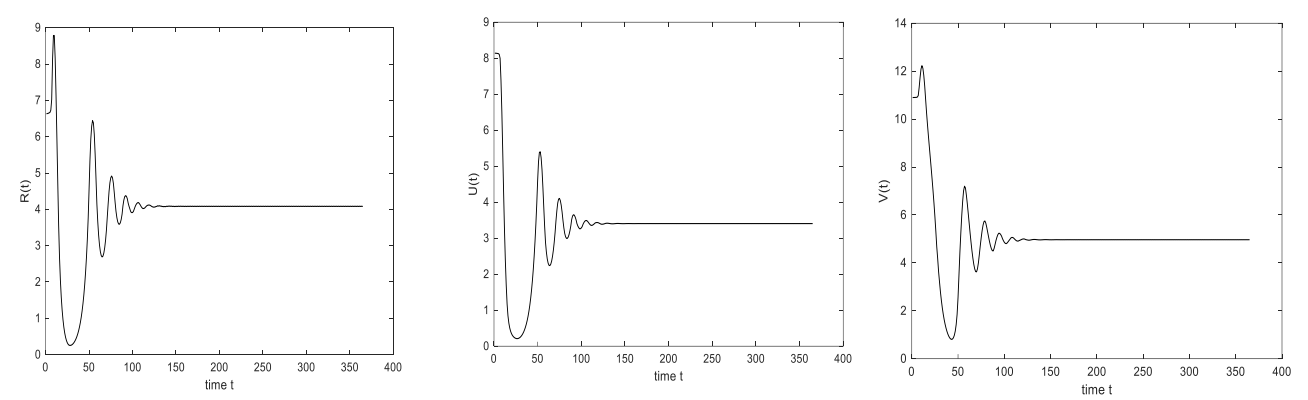

Figure 3. Trajectories of the system (2): $(t, R(t)),(t, V(t)),(t, U(t))$ when there is no delay. The equilibrium point $(7,7.93,10.97)$ is locally asymptotically stable

The critical value of the bifurcation parameter is $\tau_{0}=0.19$ and in this case, a Hopf bifurcation occurs. For any level of $\tau_{0}<0.19$ the equilibrium point $(7,7.93,10.97)$ is locally asymptotically stable. The orbits of the occurrence value of the risk, $(\mathrm{t}, \mathrm{R}(\mathrm{t}))$ the analysed value of the risk $(\mathrm{t}, \mathrm{U}(\mathrm{t}))$ and the controlled value of the risk $(\mathrm{t}, \mathrm{V}(\mathrm{t}))$ in the current state of the market are represented in the following figures: 
Preventing Contagion in Financial Markets. An Analysis of the Controlled Financial Risk with Time Delay
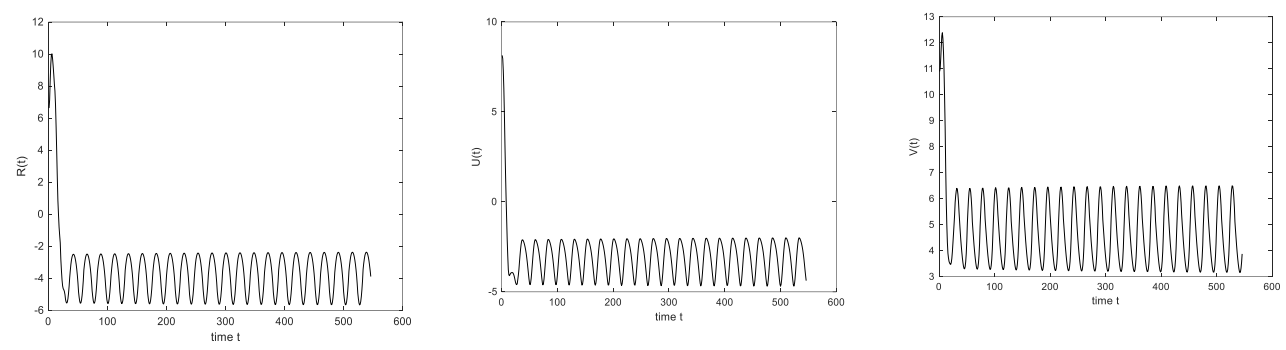

Figure 4. Trajectories of the system (2): (t, $R(t)),(t, V(t)),(t, U(t))$ are periodical for the critical value of time delay
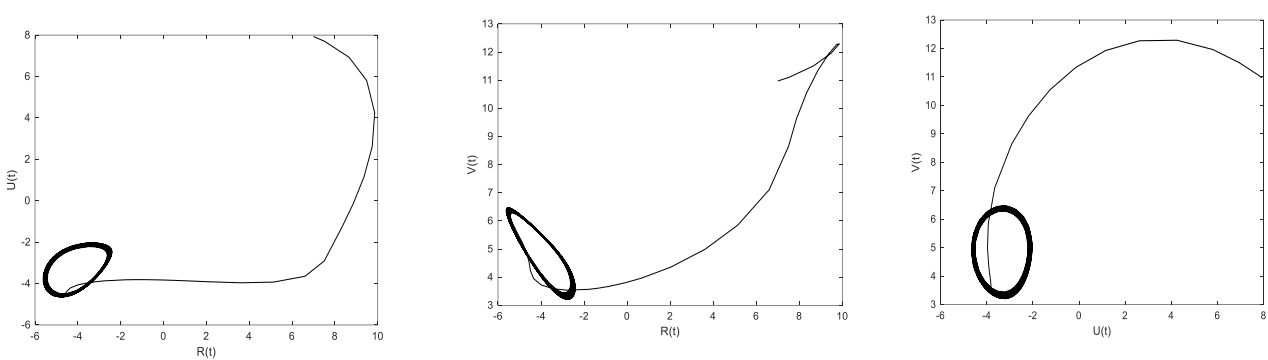

Figure 5.The orbits $(R(t), U(t)),(R(t), V(t)),(U(t), V(t))$ for the critical value of time delay. Due to the occurrence of the Hopf bifurcation a limit cycle appearance in the neighbourhood of the positive equilibrium point

\section{Conclusions}

Financial authorities are concerned with preventing the contagion of the risks from one market to another, hence an in-depth analysis is run to pinpoint the best possible moment when macro-prudential measures should be undertaken.

The present article argues that there is a causal correlation between the evolution of the analyzed risk (U), the occurrence value of the risk (R) and the controlled value of the risk in the current market $(\mathrm{V})$, and the oscillation of $\mathrm{R}(\mathrm{t})$ depends on the analysis efficiency the other risks. A time delay $\tau$ is introduced on the analyzed value of the risk to detect the optimum interval when macroprudential measures should be taken to stabilize the system and prevent contagion. The analysis also shows that the perpetuation of risks depends on the traces (tail) left by previous risks. Thus, the occurrence value of the risk includes an acceptable margin $(\mathrm{nR})$ and a possible occurrence value given by the analyzed value of the

DOI: 10.24818/18423264/54.2.20.07 
risk in a previous moment and the controlled value of the risk by the analyzed value of the risk $((\mathrm{U}(\mathrm{t}-\tau)+\mathrm{UV})$.

As numerous empirical analyses demonstrate, there are several determinants of risk contagion, e.g. shocks that are transferred from one market to another, risk transfer mechanisms, etc. Nevertheless, contagion is supported by domestic as well as external financial vulnerabilities, agents trying to prevent risk congestion and thus transfer the risks on less developed or less secured markets. When such a trend becomes obvious than policymakers, are called to apply the most appropriate measures to prevent the forthcoming crisis. Therefore, a high degree of abstraction is required for mathematical models. Since the numerical examples verify the theoretical findings, the model may be used for any market analysis.

Caveat: The perpetuation of the financial risk contagion also depends on the investors' behaviour. It is well known that when markets go through rough times agents withdraw from all markets thus blocking the smooth functioning of trading.

However accurate a risk analysis is, there remains an uncontrollable part, because of investors' behaviour. This may be induced by information asymmetries, moral hazard problem, adverse selection, investor's subjective assessment of the market (risk appetite or risk aversion) etc. The behavioural approach does not oppose mainstream financial theories but helps understand the recurrence of crises. Thus, risk analysis becomes one of the most complex and challenging issues for practitioners, policymakers and academics since timely reaction prevents contagion and the recurrence of crises.

Nonetheless, it remains to be proven to what extent the rationality or subjective perceptions (based on behavioural biases) impact on risk management and contagion.

\section{REFERENCES}

[1] Alghalith,M., Guo, X., Wong, W.K, Zhu, L. (2016),A General Optimal Investment Model in the Presence of Background Risk. Annals of Financial Economics, 11(1):1-8, DOI: 10.1142/S2010495216500019;

[2] Asgarian, H.,Nossman M. (2011), Risk Contagion among International Stock Markets. Journal of International Money and Finance, 30:22-38, DOI:10.1016/j.jimonfin.2010.06.006;

[3] Baur, D. G., Lucey B. (2009),Flights or Contagion? An Empirical Analysis of Stock-bond Correlations.Journal of Financial Stability, 5:339-352. DOI:10.1016/j.jfs.2008.08.001;

[4]Caporin, M., Pelizzon L., Ravazzolo F., Rigobon R. (2013),Measuring Sovereign Contagion in Europe.NBER Working Paper 18741; 
Preventing Contagion in Financial Markets. An Analysis of the Controlled Financial Risk with Time Delay

[5]Chen, T., Chen Y., Li X. \& Wang J. (2015),An Entropy Model of Credit Risk Contagion in the CRT Market.Discrete Dynamics in Nature and Society, 1-9. DOI:10.1155/2015/397852;

[6]Davis, P. (2003), Toward a Typology for Systemic Financial Instability. Brunel University, Discussion Papers, retrieved from http://bura.brunel.ac.uk/bitstream/2438/916/1/03-20.pdf.

[7] Donath, L., Neamțu, M., Mircea, G. (2018), International Impact of Financial System Risks. A Dynamics Analysis with Time Delay.18th International Scientific Conference Globalization and Its Socio-Economic Consequences University of Zilina, 1536-1544;

[8]Dornbusch, R., Park, Y.C.,Claessens, S. (2000),Contagion: Understanding how it Spreads.The World Bank research observer, 15(2):177-97.

DOI:10.1093/wbro/15.2.177;

[9] Fang, M., Yang, S., Lei, Y. (2019), Residual Contagion in Emerging Markets: 'Herd' and 'Alarm' Effects in Informatization. Electronic Commerce Research,Springer, 1-21.DOI:10.1007/s10660-019-09350-x; [10] Fischhoff, B., Slovic P., Lichtenstein, S. (1977),Knowing with Certainty: The Appropriateness of Extreme Confidence.Journal of Experimental Psychology: Human Perception and Performance, 3(4):552-564. DOI:10.1037//0096-1523.3.4.552;

[11]Frait, J., Komárková, Z. (2011),Financial Stability, Systemic Risk and Macroprudential Policy.Czech National Bank, Financial Stability Report 2010/2011, 96-111;

[12]Xu, G., Gao, W. (2019),Financial Risk Contagion in Stock Markets: Causality and Measurement Aspects.Sustainability, 11 (5). doi.org/10.3390/su11051402; [13]Gong, L., Smith, W., Zou, H. (2007), Asset Prices and Hyperbolic Discounting;Annals of Economics and Finance8(2): 397-414;

[14]Grosse, R. (2010),The Global Financial Crisis - A Behavioral View, retrieved from https://ssrn.com/abstract=1537744;

[15]Gulzar, S., Kayani, G. M., Xiaofeng, H., Ayub, U., Rafique A. (2019),Financial Cointegration and Spillover Effect of Global Financial Crisis: A Study of Emerging Asian Financial Markets; Economic ResearchEkonomskaIstraživanja 32(1):187-218.DOI:10.1080/1331677X.2018.1550001; [16]Haldane, A. (2009), Why Banks Failed the Stress Test, retrieved from http://www.bankofengland.co.uk/publications/speeches/2009/speech374.pdf; [17] Kahneman, D.,Tverski A. (1979),The Prospect Theory: An Analysis of Decision under Risk.Econometrica 47(2), 263-292;

[18]Karaaslani, C.C. (2012),Bifurcation Analysis and Its Applications in Numerical Simulation: From Theory to Industry. IntechOpenIntech Rijeka, Croatia, MykhayloAndriychuk ed. DOI: 10.5772/50075;

DOI: 10.24818/18423264/54.2.20.07 
Liliana Donath, Gabriela Mircea, Mihaela Neamtu, Ionela Oprea

[19]Kuznetsov, Y.A. (1998),Elements of Applied Bifurcation Theory, 2nd edition, Springer;

[20] Lutoshkin, I.V., Yamaltdinova N.R. (2018), The Dynamics Model of Advertising Costs. Economic Computation and Economic Cybernetics Studies and Research;ASE Publishing;1(52): 201:213;

[21] Mink, M., Mierau J. (2009), Measuring Stock market Contagion with an Application to the Subprime Crisis.Der Nederlandsche Bank N.V., Working Paper, 217/2009;

[22] Trabelsi, M.L., Hmida, S. (2017), A Dynamic Correlation Analysis of Financial Contagion: Evidence from the Eurozone Stock Markets, retrieved from https://mpra.ub.uni-muenchen.de/83718/MPRA Paper No. 83718;

[23] Wälti, S. (2003),Testing for contagion in International Financial Markets: Which Way to Go?,IHEID Working Papers 04, Economics Section, The Graduate Institute of International Studies, 1- 44;

[24]Zhang, X.D., Liu X.D., Zheng, Y., Liu, Cheng (2013),Chaotic Behaviour Analysis and Control for a Financial Risk System. Chin. Phys. B, 22(3), 1-6; [25] Zhang, X., Zhu,H. (2019),Hopf Bifurcation and Chaos of a Delayed Finance System. Complexity, 1-18. DOI:10.1155/2019/6715036. 